\title{
Current smoking among young adolescents: assessing school based contextual norms
}

\author{
S B Pokorny, L A Jason, M E Schoeny
}

Tobacco Control 2004;13:301-307. doi: 10.1136/tc.2003.005363

See end of article for authors' affiliations

......................

Correspondence to: Steven B Pokorny, $\mathrm{PhD}$, Center for Community Research, 990 Fullerton Avenue, Suite 3100, Chicago, illinois 60614, USA; spokorny@depaul.edu

Received 22 July 2003 Accepted 27 April 2004
Objective: To extend research on the relation of school based contextual norms to current smoking among adolescents by using three analytic techniques to test for contextual effects. It was hypothesised that significant contextual effects would be found in all three models, but that the strength of these effects would vary by the statistical rigor of the model.

Design: Three separate analytic approaches were conducted on baseline self report student survey data from a larger study to test the relation between school level perceived peer tobacco use and individual current smoking status.

Participants: A representative sample of 5399 sixth through eighth grade students in 14 midwestern middle schools completed the survey. All enrolled sixth through eighth grade students were eligible to participate in the survey. The student participation rate was $91.4 \%$ for the entire sample, and did not differ significantly between the schools (range 82-100\%).

Main outcome measure: Thirty day cigarette smoking prevalence.

Results: A level 2 only model based on aggregated individual responses indicated that students in schools with higher average reported peer tobacco use were more likely to be current smokers than students in schools with lower average peer tobacco use. Using a level 1 only model based on individual responses indicated that the effect of school level perceived peer tobacco use on current smoking was significant when individual perceived peer tobacco use was excluded from the model but was non-significant when individual perceived peer tobacco use was added to the model. A multilevel model also indicated that the effect of school level perceived peer tobacco use on current smoking was not significant when individual perceived peer tobacco use was added to the model.

Conclusion: The analytic approach used to examine contextual effects using individuals' reports of peer tobacco use norms that were aggregated to obtain a context measure of the school norms may produce statistical artefacts that distort the association of the school context in general, and peer tobacco use norms in particular, with increased risk for current smoking beyond the risk associated with individual factors.

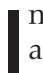
the USA, cigarette smoking is the leading cause of death, and first use of tobacco almost always occurs during adolescence. ${ }^{1}$ Moreover, the age at which youth begin smoking influences subsequent smoking patterns, including progression to regular or daily smoking, ${ }^{2}$ and the likelihood of quitting. ${ }^{3}$ Youth who begin smoking at earlier ages use larger amounts of tobacco, over longer periods of time, and have more difficulty quitting than youth who begin smoking later in life. All of these factors place youth who initiate smoking at an early age at an increased risk for developing long term serious health consequences. ${ }^{4}$

Despite more than two decades of national and local prevention efforts, the prevalence of youth tobacco use remains unacceptably high. Population estimates for persons under the age of 18 indicate that every day 5500 youth try cigarettes for the first time, and nearly 3000 more youth become daily smokers. ${ }^{5}$ The National Youth Tobacco Survey conducted by the American Legacy Foundation in 2000 indicated that the 30-day prevalence of smoking was $11 \%$ among grade 6-8 students (ages $11-14$ years) and 28\% among grade $9-12$ students (ages $15-18$ years). ${ }^{6}$ The increase in rates of current smoking from middle school to high school identifies a critical period in a youth's development when most smoking initiation occurs. ${ }^{7}$

Scientific efforts to understand and ultimately prevent youth smoking seek to identify the correlates of this dangerous behaviour. Social contexts are recognised as important influences on individual behaviour. ${ }^{8}$ An ecological analysis of adolescent behaviour seeks to understand the behaviour in the context of individual, family, peer, and environmental influences. ${ }^{9-11}$ Within this perspective, social settings (for example, family, peer, and school contexts) represent important microsystems that may interact with individual factors to influence adolescent behaviour.

Previous research identified a variety of individual risk factors to be associated with adolescent smoking status. For example, increases in age consistently relate to higher rates of smoking. ${ }^{12}{ }^{13}$ Rates of smoking also vary among different racial groups, ${ }^{14}$ with rates highest among non-Hispanic whites, followed by Hispanics, and African Americans. ${ }^{15}$ Trends in adolescent smoking over the past decade reflect different patterns of increasing and decreasing smoking initiation among males and females, ${ }^{16}$ and research suggests that sex may interact with other factors to influence adolescent smoking. ${ }^{17}{ }^{18}$ Adolescents from higher socioeconomic status families have lower rates of smoking. ${ }^{13}$ In addition, adolescents with positive attitudes toward antitobacco policies report lower rates of smoking. ${ }^{19}$

Another important risk factor is the smoking behaviour of parents and/or peers. ${ }^{20}$ The presence of an adult tobacco user in the home influences smoking among adolescents. For example, a cross sectional study of youth aged 12-14 years found that compared with adolescents whose parents never smoked, those whose parents currently smoked were nearly twice as likely to smoke. ${ }^{21}$ Friends, who smoke, in peer networks are one the strongest correlates of adolescent smoking initiation ${ }^{22}$ and continued cigarette use. $^{41213}$ 
Although the individual risk factors described above are important, it is also possible that environmental factors such as school based social norms regarding smoking may also influence adolescent smoking behaviour. Schools are important social contexts for youth that may impact adolescent behaviour by establishing and maintaining social norms that provide positive and negative consequences for behaviour. ${ }^{24}$ One approach to examine these types of environmental factors is to aggregate student perceptions of norms to obtain a context measure at the school level. A variety of approaches have been used to model school effects as aggregates of individual responses. These approaches include aggregating all variables at the school level, ${ }^{25}$ treating all variables as person specific variables, ${ }^{26}$ and combining school level and person level factors in a hierarchical model. ${ }^{27}$

For example, Ennett et $a l^{25}$ examined the relation of school and neighbourhood contexts to rates of alcohol, cigarette, and marijuana use among fifth and sixth graders in 36 elementary schools. The authors used aggregates of student reports (that is, the school mean) to reflect: (1) substance use norms, (2) attitudes about substance use, (3) perceived access to alcohol, cigarettes, and marijuana, (4) school attachment, and (5) school safety. Measures of neighbourhood characteristics were derived from aggregated parent reports and census data. Correlation analyses indicated, among findings for the other substances, that rates of lifetime cigarette use were higher in schools with greater perceived acceptability of cigarette use, higher cigarette availability, and lower school attachment. Current cigarette use was related to more positive attitudes toward substance use, and perceptions about cigarette acceptability and availability. Students' cigarette use behaviour was more similar among students within schools than between schools, and the relations between the school variables and rates of use were stronger and more consistent than were those with the neighbourhood characteristics. The authors concluded that the school context may have influenced rates of use, supporting a contagion theory of substance use.

Allison $e^{a} a^{26}$ also examined the contextual influences on stages of adolescent substance use among 283 grade 7-12 students in six schools. However, the authors included individual risk factors in their assessment of contextual factors. Two series of hierarchical multiple regression analyses were used to examine the relation of demographic variables (that is, sex, age, race, and socioeconomic status); peer and parent alcohol, tobacco, and other drug use; school norms for alcohol, tobacco, and other drug use; and school placement (that is, regular educational placement or mainstreamed special education placement) to stages of primary drug use (that is, cigarettes, alcohol, and marijuana) and secondary drug use (that is, hashish, barbiturates, cocaine, etc). School drug use norms were computed by subtracting the individual respondent's report of use from the school mean resulting in a unique measure of school context for each respondent. In the final model, only parent and peer alcohol, tobacco, and other drug use, and school norms for secondary stages of drug use were significantly related to primary stages of drug use. The authors suggest that the school context is an important developmental setting that warrants further study for its impact on adolescent drug use.

Kumar $e t$ al $^{27}$ also examined the effects of individual risk factors and school context on substance use. Specifically, the authors examined the effects of individual characteristics and the school level norm regarding disapproval of substance use, based on aggregated student responses, on substance use among nationally represented samples of students in grades 8, 10, and 12 attending 150, 140, and 142 schools, respectively. Multilevel hierarchical analyses were used to model within school and between school variance in substance use as a function of school level norms of disapproval of substance use on individual students' use, controlling for personal disapproval of substance use as well as school and individual demographic characteristics. Results suggest that school level norms of disapproval of substance use were negatively related to students' use of these substances after controlling for personal disapproval of substance use as well as school and individual demographic characteristics.

When examining the relation of school context to adolescent behaviour it is critical to have a representative sample of students within schools. High participation rates (for example, $80 \%$ or greater) are needed to avoid sampling bias, particularly when a study is focused on contextual effects and high risk behaviour. Low participation rates might introduce biases in terms of the sample characteristics as well as on important dependent variables. ${ }^{28-30}$ In the Allison et al ${ }^{26}$ study, response rates ranged from 15-25\% for five of the six schools and $72.7 \%$ for the sixth school.

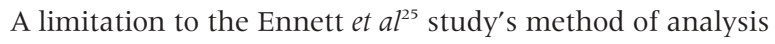
is that it aggregated individual responses for contextual measures and examined associations among the contextual factors only without accounting for individual risk factors. The Allison et al ${ }^{26}$ study examined individual risk factors and contextual factors, but did not account for the nested sample design (that is, students sampled within schools). Such sampling strategies result in dependent observations that need multilevel models to control for these nested effects. Neither the Ennett et $a 2^{25}$ or the Allison et $a^{26}$ studies employed multilevel statistical analyses to control for the dependent observations in the nested sample designs. In contrast, the Kumar et $a^{27}$ study appropriately used a random coefficient multilevel analyses to model individual, social, and environmental influences on smoking behaviour, based on nested samples. ${ }^{31-33}$

The purpose of the present study was to assess possible statistical artefacts in studies of contextual effects based on aggregated student data. The present study replicated the three analytic techniques used in the studies described above $^{25-27}$ to examine the relation of school based peer tobacco use norms on current smoking among representative samples of students from 14 middle schools. It was hypothesised that with the less rigorous statistical methods significant contextual effects would be found after controlling for individual and social risk factors. It was also hypothesised that the results would be attenuated using statistical methods that appropriately model the hierarchical structure of the data. In other words, we hypothesised that we would find significant contextual effects in all three models, but that the strength of these effects would vary by the statistical rigor of the model.

\section{METHODS}

The present study used the first wave of data (that is, baseline data) collected from a larger three year intervention study funded by the Robert Wood Johnson Foundation. ${ }^{34}$ Eleven randomly selected towns (rural, suburban, and urban) in northern and central Illinois provided baseline data. Current smoking was assessed through student self report surveys during March and April of 1999. These data were based on a two stage sample procedure, which sampled schools and then students within schools. Several towns had school districts with multiple schools and requested that all of the schools within the district participate. As a result, a total of 23 schools within the 11 towns provided baseline data for the larger study. Nine of the 23 schools had a kindergarten through sixth grade structure that fed into larger seventh to eighth grade schools. Since only the sixth grade was sampled in these schools, the nine schools were 
eliminated from the analyses because it was unlikely that the data collected accurately reflected the school environmental factors. The remaining 14 schools that had at least sixth through eighth or seventh through eighth grade structures and included all grades in the student survey were used in the analysis for the present study.

\section{Student survey}

Information about the smoking behaviour was obtained from the Youth Tobacco Access Project's Student Survey. The measure was an anonymous self report survey because the larger study was based on a cohort design of students within towns that were randomised into the intervention conditions. Approximately one week before survey administration, parents were notified by letter of the survey and given the opportunity to withdraw their children from the study. At the time of the survey administration, students were required to give written assent to participate in the study. Of the 6486 eligible students, less than $1 \%$ of the parents $(n=53)$ requested that their child not participate in the survey, and $8 \%$ of the remaining students $(n=508)$ did not participate because they were either absent or declined to participate at the time of the survey. A total of 5925 students were surveyed in 14 schools. The student participation rate was $91.4 \%$ for the entire sample, and did not differ significantly between the schools, $\chi^{2}(13, \mathrm{n}=6486)=12.4 ; \mathrm{p}=0.50$. However, 526 students were excluded from the analyses because of inconsistent or invalid responding across survey items, and/or missing data on the majority of variables or the outcome variable. The remaining 5399 students, who represented 83\% of the eligible students, comprised the final sample for the analyses.

The student survey contained 79 items adopted from other established measures of students' attitudes and behaviour toward tobacco, alcohol, and other drugs. ${ }^{35}$ Members of the research team administered surveys to students in classrooms or small groups, and students typically completed the survey in 20-25 minutes. Initial questions on the student survey involved demographic variables, date of birth, grade (for example, 6, 7, or 8), sex, racial group membership, and parents' education level. Students also reported whether they had ever tried cigarettes, the frequency that they had smoked in the 30 days before the survey, and their attitude about tobacco possession laws. In addition, they were asked if an adult tobacco user lived at home and how many of their peers used tobacco.

\section{Variables}

\section{Level 1 variables}

All level 1 variables were derived from self report data obtained from the student survey. The level l variable pertaining to current smoking was analysed as the dependent variable and the remaining level 1 variables were analysed as independent variables in the model.

\section{Current smoking}

Current smoking was coded as a dichotomous variable based on the responses to the question "During the past 30 days, on how many days did you smoke cigarettes?". Students were classified as a current smoker if they reported smoking on any of the previous 30 days.

\section{Age}

Age in years was calculated by subtracting the respondent's date of birth from the date of the survey. Age was coded as a continuous variable centred at 13 for all analyses to aid interpretation of the results.
Race

Race was determined from responses to the question "How do you describe yourself, mark all that apply (White, Black or African American, Latino or Hispanic, Asian or Pacific Islander, Native American/Alaskan Native, Other)". Because the majority of students were White, African American, or Latino, this variable was reduced to four categories (White, African American, Latino, and Other). For the present analyses, this variable was indicator (that is, dummy) coded by creating dichotomous variables indicating African American, Latino, and Other. Therefore, in all analyses, White youth are the reference group for each of the three dummy coded variables.

\section{Sex}

Sex was coded as a dichotomous variable determined from responses to the question "What is your gender? (Female or Male)."

\section{Parent education}

Parent education was scored to reflect whether either parent had attended college based on the responses to two questions: "How far did your mother go in school?" and "How far did your father go in school?" $(0=$ less than high school, 1 = high school graduate, 2 = some college, 3 = college graduate, and $4=\mathrm{I}$ don't know). The parent education variable was coded as 1 for students who reported a value of 2 (some college) or 3 (college graduate) for either parent. All other responses were coded as 0 .

\section{Attitude about tobacco possession laws}

Student attitudes about tobacco possession laws were calculated as a continuous variable determined by the response to the statement "Police should fine people under the age of 18 for using, carrying, or holding tobacco products (like cigarettes, cigars, chewing tobacco or snuff)". Responses were reported on a five point Likert scale (ranging from $1=$ strongly disagree to $5=$ strongly agree) .

\section{Adult tobacco users}

The presence of an adult tobacco user in the home was calculated as a dichotomous variable determined by the response to the question "Is there an adult living in your household who regularly uses tobacco products? (Yes or No $)^{\prime \prime}$.

\section{Peer tobacco users}

The perceived presence of peer tobacco users in the youth's life was calculated as an ordinal variable by averaging scores based on responses to the two questions "How many of your friends who are boys use tobacco products? $(0=$ none, $1=$ a few of them, 2 = some of them, $3=$ most of them, and 4 = all of them)" and "How many of your friends who are girls use tobacco products? $(0=$ none, $1=$ a few of them, 2 = some of them, $3=$ most of them, and $4=$ all of them)." The range for this variable was from 0 to 4 .

\section{Level 2 variables}

Most of the level 2 variables were created by aggregating self report data obtained from the student survey within each $\mathrm{school}^{36}$ to represent an average level of the construct for each school (that is, mean age, percentage of each racial category, percentage male, percentage with at least one parent who attended college, mean attitude toward possession laws, percentage with an adult tobacco user in the home, and the average perceived peer tobacco users). These are the same variables used as level 1 predictors and are described above. Two additional school environmental level 2 variables were obtained from the Illinois State School Report Cards. ${ }^{37}$ The 
percentage of students who were classified as low income was included in the analyses as a school level socioeconomic indicator. The school mobility rate was included in the analyses as an index for the stability of school norms. The school level mean perceived peer use is used as a contextual measure of perceived tobacco use norms. Although adolescents tend to overestimate the prevalence of smoking among peers, ${ }^{13}$ Iannotti and Bush $^{38}$ examined perceived versus actual peer use and found that perceived smoking by friends was a stronger predictor of cigarette use than actual friends use.

\section{Statistical analysis}

Three separate series of analyses were conducted to test the relation between school level perceived peer tobacco use and individual current smoking status. For the first set of analyses, the level 2 only model, we calculated level 2 (that is, school level) aggregates for all covariates. This analytical approach was used by Ennett et $\mathrm{al}^{25}$ and treats all variables in the model as school level aggregates of individually reported data. This method, however, does not permit the separation of contextual from individual influences and consequently may lead to findings of significant contextual effects that are simply the sum of individual effects. The second set of analyses, the level 1 only model, used person level covariates for all variables. School level perceived peer use in this model was calculated as the mean of all students in the school excluding the target individual. This analytic model was used by Allison et $a l^{26}$ and treats all variables in the model as individual level data. This approach also fails to separate contextual from individual influences and consequently may confound contextual findings with individual effects. For the final model, the multilevel model, a random coefficient multilevel analysis was performed using HLM 5. ${ }^{39}$ This model was used by Kumar et $a l^{27}$ and most accurately models the multilevel nature of the data (that is, school level variables and individual level variables) and nested design of sampling of students within schools ${ }^{31-33}$ Further, by separating individual and contextual effects, this approach accurately models contextual effects as above and beyond individual effects. All three models were first tested without control variables. In addition, the models were tested controlling for the individual covariates of age, race, sex, having a parent who attended college, attitudes about tobacco possession laws, adult tobacco users, and peer tobacco users.

\section{RESULTS}

Among the 14 schools participating in this study, most of the eligible students participated in the survey (mean $=91.4 \%$, range $82 \%-100 \%$ between schools $)$. In general, the schools had student populations who were primarily white $($ mean $=75.2 \%)$, had no or few peer tobacco users $($ mean $=75.2 \%)$, not of low income status $($ mean $=14.1 \%)$, and of relatively low mobility (mean $=$ $10.9 \%$ ). Although a minority of students at each school were current smokers, eight of the 14 schools had higher rates of current smoking than the national norm of $9.2 \%$ for middle school populations. ${ }^{6}$ Overall, $10.1 \%$ of students were current smokers, which is within the $95 \%$ confidence interval (CI) for the national middle school norms (95\% CI 7.6 to 10.8). These findings suggest that a representative sample was obtained from participating schools and the measured prevalence of current smoking was at a level expected based on national norms for middle school youth.

Table 1 provides the demographic information on the 5399 participating students who reported their current smoking status. Sample sizes differ slightly among the analyses due to variations in the patterns of missing data. Among this sample, students were distributed relatively evenly by grade and sex. Consistent with expected ages for students in these grades, the majority of students were between the ages of 1214 years. The sample had a majority of white youth with the remaining youth distributed between African-American, Latino, and "other" racial groups. More than one third of the sample reported having an adult tobacco user in the home, and over half of the sample reported having peers who use tobacco. The remainder of table 1 presents the number and percentage of the sample based on current smoking status. For these columns, the percentages represent the percentage of the sample within the level of current smoking at each value of the level 1 variable (for example, $2.5 \%$ of youth ages 10-11 were current smokers). These data highlight some of the relations between the level 1 variables and current smoking status assessed in the regression models.

The first series of analyses tested the level 2 only models using aggregate data for the 14 schools. In a bivariate correlation, the mean level of perceived peer use was highly correlated with the proportion of students who were current smokers $(r=0.92, \mathrm{p}<0.001)$. Given the limited sample size for these analyses (14 schools), a two step approach was used for entering variables in a multiple linear regression analysis. In the first step, control variables were added to the equation using stepwise entry. Three control variables were added in this step: mean attitudes about enforcement of possession laws, proportion of students who were African American, and proportion of students with at least one parent attending college. Mean perceived peer use was added in the second step. In the final model, mean level of perceived peer use remained significantly correlated with the proportion of students who were current smokers $(\beta=0.40$; $p<0.05$ ), controlling for the effects of mean attitudes about enforcement of possession laws, proportion of students who were African American, and proportion of students with at least one parent attending college. These results replicate the findings presented by Ennett et $a^{25}$; however, this approach did not allow us to separately test the individual and the contextual effects.

The second series of analyses tested the level 1 only models using exclusively individual level variables. In a binary logistic regression analysis, the school mean for perceived peer use (that is, excluding the target individual) was significantly related to current cigarette use (odds ratio (OR) 4.23 , 95\% CI 3.25 to $5.51 ; p<0.001)$. In the second model, a two step hierarchical binary logistic regression model was estimated. In the first step, seven individual level covariates were entered (that is, sex, grade, age, race, presence of an adult tobacco user, at least one parent attended college, and attitude about enforcement of possession laws). The aggregated perceived peer use variable was entered in the second step. In this model school level perceived peer use was significantly related to current smoking (OR 1.74, 95\% CI 1.24 to $2.44 ; \mathrm{p}=0.001$ ). This replicates the findings presented by Allison et al. ${ }^{26} \mathrm{Next}$, the individual level covariate of perceived peer use was added to the model to address an important limitation of Allison et al's analyses. In Allison et al's model, the contextual effect was calculated as the mean of everyone in the school excluding the individual respondent. In essence, this approach failed to control for the impact of the individual level covariate when modelling contextual effects. When individual level perceived peer use was added to the model (that is, a step not done by Allison et al) the individual level covariate was significant (OR 2.98, 95\% CI 0.2.63 to 3.38; p < 0.001); however, the school level effect of perceived peer use norms was no longer significant (OR 1.15, 95\% CI 0.80 to $1.65 ; \mathrm{p}=0.45$ ).

The third and final analytic approach tested a multilevel model similar to the approach used by Kumar et al. ${ }^{27}$ The first step in building this multilevel model was estimating an unconditional means model ${ }^{35}$ to test for significant between 
Table 1 Sample characteristics and relation to current smoking status

\begin{tabular}{|c|c|c|c|c|c|c|}
\hline \multirow[b]{3}{*}{ Variable } & \multirow{2}{*}{\multicolumn{2}{|c|}{ Total $(n=5399)$}} & \multicolumn{4}{|c|}{ Current smoker } \\
\hline & & & \multicolumn{2}{|c|}{ Yes $(n=527)$} & \multicolumn{2}{|c|}{ No $(n=4872)$} \\
\hline & $\mathbf{n}^{*}$ & $\% \dagger$ & $\mathbf{n}$ & $\% \ddagger$ & $\mathbf{n}$ & $\% \ddagger$ \\
\hline \multicolumn{7}{|l|}{ Grade } \\
\hline 6 & 1377 & 25.5 & 44 & 3.2 & 1333 & 96.8 \\
\hline 7 & 1991 & 36.9 & 201 & 10.1 & 1790 & 89.9 \\
\hline 8 & 2026 & 37.6 & 281 & 13.9 & 1745 & 86.1 \\
\hline \multicolumn{7}{|l|}{ Age (years) } \\
\hline 10,11 & 590 & 10.9 & 15 & 2.5 & 575 & 97.5 \\
\hline 12 & 1519 & 28.1 & 82 & 5.4 & 1437 & 94.6 \\
\hline 13 & 2018 & 37.4 & 221 & 11.0 & 1797 & 89.0 \\
\hline 14 & 1191 & 22.1 & 189 & 15.9 & 1002 & 84.1 \\
\hline 15,16 & 81 & 1.5 & 20 & 24.7 & 61 & 75.3 \\
\hline \multicolumn{7}{|l|}{ Race } \\
\hline White & 4108 & 76.1 & 387 & 9.4 & 3721 & 90.6 \\
\hline African American & 316 & 5.9 & 42 & 13.3 & 274 & 86.7 \\
\hline Latino & 420 & 7.8 & 63 & 15.0 & 357 & 85.0 \\
\hline Other & 555 & 10.3 & 35 & 6.3 & 520 & 93.7 \\
\hline \multicolumn{7}{|l|}{ Sex } \\
\hline Female & 2706 & 50.1 & 265 & 9.8 & 2441 & 90.2 \\
\hline Male & 2693 & 49.9 & 262 & 9.7 & 2431 & 90.3 \\
\hline \multicolumn{7}{|c|}{ One or both parents attended college } \\
\hline No & 2444 & 45.3 & 341 & 14.0 & 2103 & 86.0 \\
\hline Yes & 2955 & 54.7 & 186 & 6.3 & 2769 & 93.7 \\
\hline \multicolumn{7}{|c|}{ Support tobacco possession laws } \\
\hline Strongly disagree & 541 & 10.0 & 229 & 42.3 & 312 & 57.7 \\
\hline Disagree & 601 & 11.1 & 141 & 23.5 & 460 & 76.5 \\
\hline Neutral & 985 & 18.2 & 87 & 8.8 & 898 & 91.2 \\
\hline Agree & 1425 & 26.4 & 43 & 3.0 & 1382 & 97.0 \\
\hline Strongly agree & 1847 & 34.2 & 27 & 1.5 & 1820 & 98.5 \\
\hline \multicolumn{7}{|l|}{ Adult users } \\
\hline No & 3270 & 60.6 & 181 & 5.5 & 3089 & 94.5 \\
\hline Yes & 2129 & 39.4 & 346 & 16.3 & 1783 & 83.7 \\
\hline \multicolumn{7}{|l|}{ Peer users } \\
\hline None & 2076 & 38.5 & 8 & .4 & 2068 & 99.6 \\
\hline A few & 1557 & 28.8 & 64 & 4.1 & 1493 & 95.9 \\
\hline Some & 1439 & 26.7 & 288 & 20.0 & 1151 & 80.0 \\
\hline Most & 282 & 5.2 & 143 & 50.7 & 139 & 49.3 \\
\hline All & 45 & .8 & 24 & 53.3 & 21 & 46.7 \\
\hline
\end{tabular}

school variation in current smoking. This model indicated significant between school variation in current tobacco use $\left(\chi^{2}[13, \mathrm{n}=5721]=146.5, \mathrm{p}<0.001\right)$ which suggested that it was appropriate to investigate potential school level covariates to explain the variation. In the next step, we added the school level mean perceived peer use to the model as a level 2 covariate. School level mean perceived peer use was selected as the initial level 2 covariate because perceived peer smoking is one of the strongest correlates of smoking behaviour ${ }^{12} 132223$ and as an aggregated level 2 covariate it can be considered a measure of social context based on social learning theory. Mean perceived peer use significantly correlated with current tobacco use (OR 4.27; $t(12)=8.09$, $\mathrm{p}<0.001$ ). Next, seven individual level covariates (sex, grade, age, race, presence of an adult tobacco user, at least on parent attended college, and attitude about enforcement of possession laws) were added to the model. Controlling for these level 1 covariates, school level mean perceived peer use remained a significant predictor of current tobacco use (OR 1.74; $t(12)=2.82, \mathrm{p}=0.02)$. Finally, individual level perceived peer use was added to the model to fully replicate the approach used by Kumar et al. Following the protocol described by Raudenbush and Bryk ${ }^{38}$ the level 1 perceived peer use was centred on the grand mean to allow direct interpretation of the compositional effect for the school level mean perceived peer use. In this model, although level 1 perceived peer use was a significant correlate of current tobacco use $($ OR 3.01; $t(5382)=17.1, \mathrm{p}<0.001)$, the aggregate school level perceived peer use was non-significant $(\mathrm{OR} 1.07 ; t(12)=0.29, \mathrm{p}=0.77)$. This result is in contrast to the findings of Kumar et al, which showed a significant contextual effect when controlling for the individual level covariate.

\section{DISCUSSION}

The present study extends previous research on the relation between school based contextual norms and current smoking among adolescents. Three analytic approaches were used to test for contextual effects on current smoking among youth. These approaches included a level 2 only model that aggregated all variables at the school level ${ }^{25}$; a level 1 only model that treated all variables as person specific variable ${ }^{26}$; and a multilevel model that included school level as well as person level factors in a hierarchical model. ${ }^{27}$ Findings from this study suggest that some analytic approaches used to examine contextual effects like school based peer tobacco use norms may produce statistical artefacts. The results of these analyses indicated that it is possible to inadvertently distort the association of the school context in general, and of peer tobacco use norms in particular, with increased risk for current smoking beyond the risk associated with individual factors. Inaccurate findings may occur when the analytic approaches do not simultaneously model both contextual factors and individual risk factors. This issue is of particular importance when the purpose of the study is to make 
inferences about the relation of social contexts, such as school norms, to individual risk for current smoking.

When the analytic approach tested the level 2 only model based on aggregated individual responses, students in schools with higher average reported peer tobacco use norms were more likely to be current smokers than students in schools with lower average peer tobacco use. This finding suggests that the school level average of peer tobacco use may account for a significant proportion of between school variation in current tobacco use. Ennett et $a l^{25}$ used a level 2 only model to examine school norms regarding attitudes toward substance use and perceptions about cigarette acceptability/availability and also found significant contextual effects. These findings are consistent with the belief that social environmental contexts can have significant effects on youth development and risk behaviour. ${ }^{840}$ However, an important problem with this analytic model is that it only permits examination of the associations among contextual factors and fails to account for the effects of individual risk factors. For example, it is possible that more proximal individual risk factors, like the number of friends who use tobacco, may have a stronger association with current smoking than more distal contextual factors like school based peer use norms.

The analytic approach that tested the level 1 only model indicated that the effect of school level perceived peer tobacco use norms on current smoking was significant when individual perceived peer tobacco use was excluded from the model. This approach replicated Allison et al' ${ }^{26}$ study, which tested a level 1 only model to examine individual and contextual influences on stages of adolescent substance use. Allison et al found that school norms of secondary stages of drug use and school placement accounted for a significant amount of the variance in primary drug use. Because the approach used by Allison et al did not control for the potential confound of individual level effect on the corresponding school level effect, an additional model was tested that included the individual level measure of perceived peer use. The inclusion of an individual level covariate corresponding to the aggregated school level covariate is a key distinction between the model tested by Allison et al and the additional level 1 only model tested in the present study. When an individual level covariate was included in the model, the contextual effect of school level perceived peer use norms was no longer significant. An additional problem with the level 1 only model is that it does not control for the nested sample design (that is, students sampled with in schools). Such sampling strategies result in dependent observations that need multilevel models to control for these nested effects.

A multilevel model also indicated that the effect of school level perceived peer tobacco use on current smoking was significant when individual level perceived peer tobacco use was excluded from the model, but was not significant when individual level perceived peer tobacco use was included in the model. Kumar $e t a^{27}$ used a similar analytic approach to examine the effects of individual risk factors and school context on substance use and found that school based norms regarding disapproval of substance use, after controlling for their own disapproval and school demographics, reduced the probability of students' use of these substances. It is possible that the present study was unable to replicate these findings because of the limited sample of 14 schools, in contrast to Kumar et al's study that included a more diverse and representative national sample of schools. Kumar et al's findings suggest that there is a school level contextual influence on individual behaviours that operates directly upon the individual as well as through the attitudes and behaviours of the individual's peer group.

\section{What this paper adds}

The present study extends previous research on the relation between school based contextual norms and current smoking among adolescents. Three analytic approaches were used to test for contextual effects on current smoking among youth. These approaches included a level 2 only model that aggregated all variables at the school level; a level 1 only model that treated all variables as person specific variables; and a multilevel model that included school level as well as person level factors in a hierarchical model. Findings from this study suggest that some analytic approaches used to examine contextual effects like school based peer tobacco use norms may produce statistical artefacts. The results of these analyses indicated that it is possible to inadvertently distort the association of the school context in general, and of peer tobacco use norms in particular, with increased risk for current smoking beyond the risk associated with individual factors. Inaccurate findings may occur when the analytic approaches do not simultaneously model both contextual factors and individual risk factors. This issue is of particular importance when the purpose of the study is to make inferences about the relation of social contexts, such as school norms, to individual risk for current smoking.

There were several methodological limitations in the present study. The present study was based on a cross sectional research design, and thus it was not possible to make conclusions about causality. Furthermore, studies seeking to assess the effects of contextual factors, like schools, need to have large and varied samples of schools. It is possible that the present study was unable to replicate the findings of Kumar $\mathrm{et}^{\mathrm{l}^{27}}$ because of the relatively limited number of schools sampled (14 v 432, respectively). In addition, the selection of the contextual measure, school based perceived peer tobacco use, was based on previous research and a theoretical focus on social learning theory. However, there may be a range of other school based contextual factors that impact risk for current smoking. For example, Wakefield et a ${ }^{41}$ found strong enforcement of school tobacco policies was related to reduced rates of youth tobacco use. Our inability to obtain a significant school level effect in the present analyses may be that the peer group influence was more salient to individual behaviour and our selection of a variable that measured perceptions of peer behaviour may pose some difficulties with finding school level effects. Ideally, measures of school context should be obtained from multiple sources (for example, review of school records, teacher reports) rather than relying solely on the aggregation of student level self report data.

The present study demonstrated that tests of the relation between school based contextual norms and current smoking among adolescents may produce distorted results if inappropriate data analytic approaches are used. In the present study there was significant variability in rates of current smoking between schools, which suggested that there were contextual factors affecting individual risk for being a current smoker. These effects were significant in all models when only the school level covariate was included. However, in the level l only model and the multilevel model, the addition of the individual level covariate to the model resulted in non-significant school level effects. Future research needs to include relatively large samples of schools and employ multilevel analyses that include both contextual variables, based on aggregated data, and individual level variables. Such designs could to increase our understanding of how social contexts like schools can impact adolescent 
development and decisions about tobacco use. Confirmation of contextual effects on risk for smoking would have important implications for future prevention programmes.

\section{ACKNOWLEDGEMENTS}

The authors appreciate the funding provided by the Robert Wood Johnson Foundation Substance Abuse Policy Research Program. In addition, the authors thank the administration, staff, and students in the 14 participating schools as well as the city and police officials in the 11 participating communities for their collaboration and cooperation with this study.

\section{Authors' affiliations}

S B Pokorny, L A Jason, DePaul University, Chicago, Illinois, USA

M E Schoeny, University of Illinois at Chicago, Chicago, Illinois, USA

\section{REFERENCES}

1 Centers for Disease Control. Incidence of initiation of cigarette smokingUnited States 1965-1996. MMWR Morb Mortal Wkly Rep 1998;47:837-40.

2 Everett SA, Warren CW, Sharp D, et al. Initiation of cigarette smoking and subsequent smoking behavior among U.S. high school students. Prev Med 1999:29:327-33.

3 Breslau N, Peterson EL. Smoking cessation in young adults: age at initiation of cigarette smoking and other suspected influences. Am J Public Health 1996;86:214-20.

4 US Department of Health and Human Services. Preventing tobacco use among young people. A report of the Surgeon General, 1994. Atlanta, Georgia: Public Health Service, Centers for Disease Control and Prevention, Office on Smoking and Health, 1994. (US Government Printing Office Publication No S/N 017-001-00491-0.)

5 Gilpin EA, Choi WS, Berry C, et al. How many adolescents start smoking each day in the United States? J Adolesc Health 1999;25:248-55.

6 Centers for Disease Control and Prevention. CDC Surveillance Summaries. MMWR Morb Mortal Wkly Rep 2000;49:SS-10.

7 Winkleby MA, Fortmann SP, Rockhill B. Cigarette smoking trends in adolescents and young adults: The Stanford five-city project. Prev Med 1993:22:325-34

8 Moos RH. Social contexts: transcending their power and their fragility. Am J Comm Psychol 2003;31:1-13

9 Bronfenbrenner U. Toward an experimental ecology of human development. Am Psychol 1977;32:513-31.

10 Kelly JG. Toward an ecological conception of preventive interventions. In: Carter JW Jr, ed. Research contributions from psychology to community mental health. New York: Behavioral Publications, 1968:75-99.

11 Moos RH. Social ecological perspectives on health. In: Stone GC, Cohen F, Adler NE, eds. Health psychology: A handbook. San Francisco: Jossey-Bass, 1979:523-47.

12 O'Loughlin J, Paradis G, Renaud L, et al. One-year predictors of smoking initiation and of continued smoking among elementary schoolchildren in multiethnic, low-income, inner-city neighbourhoods. Tobacco Control 1998;7:268-75.

13 Tyas SL, Pederson LL. Psychosocial factors related to smoking: a critical review of the literature. Tobacco Control 1998;7:409-20.

14 Wallace JM, Forman TA, Guthrie BJ, et al. The epidemiology of alcohol, tobacco and other drug use among black youth. J Studies Alcohol 1999:60:800-9.

15 US Department of Health and Human Services. Tobacco use among U.S racial/ethnic minority groups: African Americans, American Indians and Alaska Natives, Asian Americans and Pacific Islanders, Hispanics. A report of the Surgeon General, 1998. Atlanta, Georgia: Centers for Disease Control and Prevention, Office on Smoking and Health, 1998. (US Government Printing Office Publication No S/N 017-001-00527-4.)
16 Anderson C, Burns DM. Patterns of adolescent smoking initiation rates by ethnicity and sex. Tobacco Control 2000;9(suppl II):ii4-8.

17 Chalupka FJ, Pacula RL. Sex and Race differences in young people's responsiveness to price and tobacco control policies. Tobacco Control 1999;8:373-7.

18 Clayton S. Gender differences in psychosocial determinants of adolescent smoking. J School Health 1991;61:115-20.

19 Unger JB, Rohrbach LA, Howard KA, et al. Attitudes toward anti-tobacco policy among California youth: associations with smoking status, psychosocial variables and advocacy actions. Health Ed Research 1999;14:751-63.

20 Bauman KE, Carver K, Gleiter K. Trends in parent and friend influence during adolescence: the case of adolescent cigarette smoking. Addict Behav 2001;26:349-61.

21 Bauman KE, Foshee VA, Linzer MA, et al. Effect of parental smoking classification on the association between parental and adolescent smoking. Addict Behav 1990;15:413-22.

22 Institute Of Medicine. Growing up tobacco free: preventing nicotine addiction in children and youths. Washington DC: National Academy Press, 1994.

23 Jackson C. Initial and experimental stages of tobacco and alcohol use during late childhood: Relation to peer, parent, and personal risk factors. Addict Behav 1997;22:685-98.

24 Anderson C. The search for school climate: a review of the research. Am Educat Res J 1982;52:368-420.

25 Ennett ST, Flewelling RL, Lindrooth RC, et al. School and neighborhood characteristics associated with school rates of alcohol, cigarette, and marijuana use. J Health Soc Behavior 1997;38:55-71.

26 Allison KW, Crawford I, Leone PE, et al. Adolescent substance use: Preliminary examinations of school and neighborhood context. Am J Comm Psychol 1999;27:111-41.

27 Kumar R, O'Malley PM, Johnston LD, et al. Effects of school-level norms on student substance use. Prev Science 2002;38:55-71.

28 Anderman C, Cheadle A, Curry S, et al. Selection bias related to parental consent in school-based survey research. Eval Rev 1995; 19:663-74.

29 Kearney KA, Hopkins RH, Mauss AL, et al. Sample bias resulting from a requirement for written parental consent. Public Opin Quart 1983;47:96-102.

30 Severson HH, Ary DV. Sampling bias due to consent procedures with adolescents. Addict Behav 1983;8:433-7.

31 Snijders TAB, Bosker R. Multilevel analysis: an introduction to basic and advanced multilevel modeling. Thousand Oaks, California: Sage Publications, 1999.

32 White H. Maximum likelihood estimation of misspecified models. Econometrica 1982;50:1-25.

33 Cohen J, Cohen P, West SG, et al. Applied multiple regression/correlation analysis for the behavioral sciences, 3rd ed. Mahwah, New Jersey: Lawrence Erlbaum Associates, 2003

34 Jason LA, Pokorny SB, eds. Preventing youth access to tobacco. New York: Haworth, 2002

35 Jason LA, Pokorny SB, Schoeny M. Evaluating the effects of enforcements and fines on youth smoking. Crit Public Health 2003;13:33-45.

36 Singer JD. Using SAS PROC MIXED to fit multilevel models, hierarchical models, and individual growth models. J Educat Behav Stat 1998;24:323-55.

37 Illinois State Board of Education. Illinois School Report Card, 1999; Retrieved January 14, 2003 from http://206.166.105.128/ReportCard/ RCHOME.asp.

38 Iannotti RJ, Bush PJ. Perceived vs. actual friends' use of alcohol, cigarettes, marijuana, and cocaine: which has the most influence? J Youth Adolesc 1992;21:375-89.

39 Raudenbush S, Bryk A, Cheong YF, et al. HLM 5: Hierarchical linear and nonlinear modeling. Lincolnwood, Illinois: Scientific Software International, Inc, 2000.

40 Dryfoos J. Adolescents at risk: prevalence and prevention. New York: Oxford University Press).

41 Wakefield MA, Ruel EE, Chaloupka FJ, et al. Effect of restrictions on smoking at home, at school, and in public places on teenage smoking: cross sectional study. BMJ 2000;321:333-7. 